\title{
From optimism to disillusion about commitment to transparency in the medico-industrial complex
}

\author{
lain Chalmers
}

J R Soc Med 2006;99:337-341

In the mid-1970s, I was involved with others in trying to assemble evidence about the effects of care during pregnancy and childbirth. We started by searching Medline to identify reports of controlled trials that we thought might be sufficiently reliable to be taken into account in our analyses; and then searched about 70 journals by hand, page by page, back to the issues published in 1950 . We found about 3500 reports of controlled trials and, with help from the World Health Organization, we published the references to these in a classified bibliography in the mid1980s. ${ }^{1}$

But then we thought, 'What about trials that don't get published? If we don't take those into account, we might reach biased conclusions'. We knew of anecdotes about researchers who had had disappointing results of trials, and had therefore never made the results public. Furthermore, in an important analysis of controlled trials of treatments for cancer of the ovary published in 1986, an Australian oncologist, John Simes, had shown how failure to publish clinical trials could lead to misleading inferences about the effects of treatments. ${ }^{2}$ So we wrote to 42000 obstetricians, paediatricians and other clinicians around the world to try to flush out information about studies that had been done but had never been reported. It was an almost complete waste of time; we published our experience to warn others to think carefully before using the retrospective survey approach we had used in our attempt to deal with publication bias. $^{3}$

Like John Simes before us, we concluded that a prerequisite for tackling the problem of biased underreporting of research involved registering controlled trials publicly, at inception, before their results could influence whether or not the world would come to know about them. In 1990, based on a paper I had presented at the 1st Congress on Peer Review in Biomedical Publishing, I published an article with the deliberately provocative title 'Underreporting research is scientific misconduct'. I suggested that failing to report well-conducted clinical trials was not only scientific misconduct, but also unethical; it broke an implicit contract with the patients who had

Editor, James Lind Library

E-mail: ichalmers@jameslindlibrary.org participated in clinical trials. I reiterated the call for registration of trials at inception. ${ }^{4}$

As it happens, all the examples of biased underreporting of controlled trials I gave in that paper referred to non-commercial trials. The drug industry is not very interested in perinatal healthcare, the field in which I was researching at that time, because it does not offer very rich pickings. Ten years before my article was published, however, Elina Hemminki had shown that biased underpublication of studies funded by industry might be a particular cause for concern. ${ }^{5}$ She compared the study reports submitted by pharmaceutical companies to drug licensing authorities with subsequently published reports of the same studies. From this she found that studies in which the pre-licensing records showed that researchers had looked for adverse effects were less likely to be published than studies in which adverse effects had not been sought.

For the reasons already mentioned, I had had little contact with the pharmaceutical industry while I was a perinatal researcher. In 1992, however, I moved to the UK Cochrane Centre. As the Centre and then the Cochrane Collaboration began to become known to people in industry, representatives of the Association of the British Pharmaceutical Industry asked to meet with me. A delegation came to the UK Cochrane Centre, led by Frank Wells, the medical director of the ABPI. Our discussion lasted for about $3 \mathrm{~h}$, during which I emphasized the openness with which the Cochrane Collaboration did its work: protocols for Cochrane reviews and completed reviews were published in electronic form, and could be criticized publicly, and readily amended if necessary.

After I had explained this, I felt it reasonable to suggest to my ABPI visitors that industry should be more open about its clinical research, because biased under-reporting could harm patients. Encouragingly, Frank Wells subsequently wrote in the preface of a book he had co-authored on fraud and misconduct in medical research: 'Underreporting of research is (another) form of misconduct, given that this can lead to seriously misleading recommendations for clinical practice and for new research' ${ }^{6}$

The same year that this book was published, Mike Wallace, another member of the ABPI delegation and at that time the chief executive of Schering Healthcare Ltd 
(the British subsidiary of Schering AG), told me that he realized that biased under-reporting of research was ethically and scientifically indefensible. He felt that unless the pharmaceutical industry started to take an initiative to confront this issue voluntarily it would end up being forced to do so-probably in ways that it would rather not be. Mike Wallace said that he had decided to provide information about all his company's controlled trials for publication in the Cochrane Controlled Trials Register. I know that he was reprimanded for breaking ranks in this way, in particular, by colleagues from other member companies of the ABPI. I am glad to be able to pay tribute to a senior nonmedical executive in the industry who stepped out of line to do something which he thought was morally correct.

Mike Wallace was not the only person within the British pharmaceutical industry taking steps towards greater openness, however. In particular, David Jackson, medical director of the British holding company of GlaxoWellcome, had persuaded his colleagues in the international parent company that the company should adopt a more open policy. The new policy was announced at the end 1997, and I was pleased to be quoted in the press release welcoming it. The following year, the chief executive of the company, Richard Sykes, wrote a landmark editorial in the $B M J$ entitled 'Being a modern pharmaceutical company involves making information available on clinical trials programmes'. He made clear that one reason for Glaxo Wellcome's new disclosure policy was '. . . to help those undertaking systematic reviews of clinical data and to help reduce the impact of publication bias'. ${ }^{7}$

GlaxoWellcome implemented the trials registration policy it had announced, and two of the people who were involved-Trevor Gibbs and Elizabeth Wager-later published an account of the challenges this had presented. ${ }^{8}$ Elizabeth Wager was head of the writers' group within the company and she convened a group of her colleagues in other companies to agree and then publish guidelines for good publication practice. They noted that '. . . the aim of the guidelines is to ensure that clinical trials sponsored by pharmaceutical companies are published in a responsible and ethical manner. The guidelines cover companies' responsibilities to endeavour to publish results of all studies' 9,10

Things were stirring among pharmaceutical physicians more widely. In 1998 the Ethics Committee of the Faculty of Pharmaceutical Medicine declared that:

'Pharmaceutical physicians have a particular ethical responsibility to ensure that the evidence on which doctors should make their prescribing decisions is freely available . . the outcome of all clinical trials on a medicine should be reported'. ${ }^{11}$

Two years later they reiterated the ethical principle: 'Studies are performed to increase knowledge in some way, and this knowledge should be shared with the wider world. Study findings should be communicated, whatever the outcome, for the benefit of the community at large'. ${ }^{12}$

Presumably because the ABPI felt that it could not really sit by while one of its major members, GlaxoWellcome, and the Ethics Committee of the Faculty of Pharmaceutical Medicine were showing a moral lead in this way, the Association decided to commend Glaxo Wellcome's policy to other member companies. I was on the ABPI side of the table at the press conference announcing this policy, and I welcomed it wholeheartedly. In brief, I had become optimistic that the industry really was beginning to address the problems that I had urged should be addressed at our meeting eight years previously. Although the response was not nearly as good as the ABPI had hoped, AstraZeneca, Aventis, MSD, Novartis, Roche, Schering Healthcare and Wyeth did begin registering retrospectively those of their trials that had involved UK patients.

However, these hopeful signs were not sustained during subsequent developments. In the same year that the ABPI announced that it was leading the world in registering clinical trials, Glaxo Wellcome merged with Smith Kline Beecham. Initially, my optimism that the new company would maintain Glaxo Wellcome's policies on trial registration seemed justified: the new company's logo had replaced the Glaxo Wellcome logo on the trials register. I wrote to the chief executive of the merged company, Jean-Paul Garnier, to express my pleasure at this. I also mentioned that I was delighted that Elizabeth Wager and her six colleagues in the former. Glaxo Wellcome writing department, and their association with the Good Publication Practice for Pharmaceutical Companies Guidelines, continued to be supported by the new company. I never received a reply to my letter; the company abandoned the trial registration process and abolished its publications departments in the USA and the UK, headed by Elizabeth Wager and Elizabeth Field, respectively-both co-authors of the Good Publication Practice Guidelines for Pharmaceutical Companies. ${ }^{9,10}$

It was round about that time that increasing amounts of empirical evidence began to confirm doubts about the trustworthiness of research sponsored by industry. As I have noted already, Elina Hemminki had produced evidence of based under-reporting of industry research 20 years earlier: reports of studies submitted in support of new drug licences in which adverse effects had been sought were less likely subsequently to be published. ${ }^{5}$ A study using similar methods was reported in 2003 by Melander and his colleagues. ${ }^{13}$ Their paper entitled 'Evidence b(i)ased medicine - selective reporting from studies sponsored by pharmaceutical industry' demonstrated result-dependent over-reporting and under-reporting of industry studies of new drugs. They concluded that any attempt to develop treatment 
recommendations using analyses based only on publicly available data were likely to be based on biased evidence.

Other evidence reported over the past 5 years has demonstrated associations between industry-sponsorship and research results favouring products made by the companies funding the research. As well as biased underreporting of research, the associations observed may also reflect inappropriate comparison of new products with comparators of existing products in doses too low to be effective or higher than necessary, with consequent higher incidence of adverse effects. ${ }^{14-17}$ Neither of these possible explanations is morally or scientifically defensible. In addition, there is evidence of more subtle forms of industry bias in the way that data are interpreted, ${ }^{18,19}$ for example, by putting a biased spin on the evidence. The title of a recent report ${ }^{20}$ says it all: 'Why olanzapine beats risperidone, risperidone beats quetiapine, and quetiapine beats olanzapine: an exploratory analysis of head to head comparison studies of second generation anti-psychotics'. One of the five key points emerging from the evidence presented at the 5th Congress on Peer Review in Biomedical Publishing was that '. . . the drug industry is successfully skewing the literature in its favour' ${ }^{21}$

By now the public was starting to get interested in these matters. I was asked to write an article about underreporting of research for the popular weekly journal New Scientist. ${ }^{22}$ In fact, I had co-authored a piece on the topic in the same journal 8 years previously. ${ }^{23}$ But now, something happened which made a real difference to the likelihood of the message about publication bias being taken seriously. Eliot Spitzer, the attorney general for New York State, took GlaxoSmithKline to court for withholding information about important possible adverse effects of drugs taken by children for depression.

The company settled out of court for a couple of million dollars, but the charge laid against it had the effect of increasing the pressure to deal with publication bias. It provoked the International Committee of Medical Journal Editors to do what the Committee should have done years earlier. It announced that the authors of any reports of clinical trials that had begun recruitment after the middle of 2005 would have to confirm that the studies had been registered publicly, at inception.

Only then did the drug industry start to try to limit the damage caused by its failure to follow the lead given by Schering Healthcare and Glaxo Wellcome nearly a decade earlier. In a press release issued in June 2004, GlaxoSmithKline announced that it would make the results of all its clinical trials publicly available. The company did not explain how, given that its trials register had been allowed to fall into disrepair, the public would know whether all results were being made available. A BMJ editorialist commented thus:
'Last month GlaxoSmithKline announced that it would publish summaries of all its clinical trials of a new product once it had been launched. The decision followed news of a lawsuit brought by New York State alleging that the company had concealed the results of paroxetine because they might have spoiled marketing plans. GSK said it had been considering the move for some months. A similar sounding policy was announced by Glaxo Wellcome in 1998, but seems to have been quietly abandoned in 2000 after the merger with SmithKlineBeecham. ${ }^{24}$

Industry's attempts at damage limitation continue. Speaking on the BBC Radio 4 programme In Business on 24 June 2005, Jean-Pierre Garnier said: 'We have responsibilities beyond those to our shareholders', and '... we must be completely transparent with the public about what we do'. The gap between this statement and an analysis of the records submitted by his company (and other pharmaceutical companies) to the National Institutes of Health trials register ${ }^{25}$ suggests that GlaxoSmithKline's understanding of what transparency implies may leave many people disappointed and cynical about the company's expressed commitment to greater openness.

If GlaxoSmithKline really is committed to the kind of openness the public has come to realise is needed, one might have expected it to have endorsed the Good Publication Practice for Pharmaceutical Companies Guidelines developed by its dismissed former employees and colleagues in other companies. ${ }^{9}$ It has not. Indeed, at the time of writing, only six pharmaceutical companies have endorsed the guidelines-Aventis, Amgen, LEO Pharma, Otsuka, Serono and 3M Pharmaceuticals. ${ }^{10}$

The public is beginning to demand stronger sanctions. During 2004 and 2005, the Health Committee of the House of Commons held an enquiry into the influence of the pharmaceutical industry. The Committee drew attention to the problem of biased under-reporting of research and recommended registration of trials at inception. ${ }^{26}$ Richard Sykes, previously chief executive of Glaxo Wellcome, now rector of Imperial College London, gave oral evidence to the Committee which clearly impressed the members. In its report, the Committee's recommendations began by noting Richard Sykes' view that:

'Today the industry has got a very bad name. That is very unfortunate for an industry that we should look up to and believe in, and that we should be supporting. I think there have to be some big changes.'

On 6 January 2005, the industry announced a global commitment to clinical trial registration and publication. Whether this commitment amounts to the 'big changes' that Richard Sykes judges are needed is an open question. First, the commitment applies to only a tiny proportion of 
the clinical trials which should be informing prescribing practices because it is not being applied to trials conducted in the past. Second, there is a continuing flow of empirical evidence of biased reporting and interpretation of industry trials. My judgement is, therefore, that industry's actions are simply too little and too late to deal with its current reputation for being less than honest with its research-just as Mike Wallace feared might be the case in his conversations with me a decade ago.

Biased under-reporting of research harms and sometimes kills patients, quite apart from the waste of resources that results from this form of scientific and ethical misconduct. In 2004, a former editor of the New England Journal of Medicine published a book entitled The Truth About The Drug Companies: How They Deceive Us and What To Do About It. ${ }^{27}$. How can we expect the public to trust the pharmaceutical industry and clinical researchers who work with it while we acquiesce in this state of affairs?

Jan Vandenbroucke has noted how science as an errordetecting process simply ceases to exist in these circumstances:

'In all scientific debates all sides always have their own biases: we have no other way to look at data but to interpret them. However, in usual clinical or epidemiologic research, studies are repeated by others, in different settings and by different means, looking for biases, flaws, and ways of remedying them, endlessly arguing whether the biases are remedied or not. That is the essence of open scientific debate and criticism, which is the only guarantee for progress. That is no longer possible with pharmaceutical products because the monopoly of the pharmaceutical industry of studies of its own products leads to persistently one-sided studies that can no longer be questioned by studies from other sides. Moreover, the one-sidedness cannot be seen from the public record, that is the published papers. Without the possibility of open debate, science simply ceases to exist'. ${ }^{28}$

Careful thought needs to be given to this analysis by governments, public and charitable organizations, and individuals who promote research collaboration with industry while remaining silent about the unethical and unscientific behaviours alluded to above. As I have made clear, biased reporting and lack of transparency is not limited to commercially-sponsored research; but the empirical evidence makes clear that it is a particularly noticeable problem in that sphere. Those who collaborate with industry need to be clear that their acquiescence in these forms of scientific misconduct inevitably casts doubt on their integrity, as reflected in the title of a book by another former editor of the New England Journal of Medicine - On The Take: How Medicine's Complicity With Big Business Can Endanger Your Health. ${ }^{29}$ The responsibilities of doctors should be unambiguously to their patients. Yet some clinician researchers (with plenty of encouragement from government and the institutions with which they are associated) appear to have become so seduced by the financial rewards resulting from collusion with industry's agenda and practices that they have forgotten this most fundamental of their professional duties. Indeed, that is the most depressing cause of my optimism of a decade ago becoming disillusionment today.

A few weeks before finalizing a draft of this essay for submission to the Journal of the Royal Society of Medicine I was invited by Richard Tiner, medical director of the ABPI, to address a meeting of 60 or so members of medical departments of member companies on the topic of 'clinical trial transparency'. In response I suggested that, rather than give a talk, it might be a more useful to pre-circulate the above text so that it could be discussed at the meeting, and Dr Tiner accepted this proposal.

It came as a bit of a surprise to me that there was no serious challenge to the facts I had assembled to explain why my earlier optimism had turned to disillusion. This may have been partly because it was clear that I have tried to work with industry over the past decade to increase transparency, and to commend publicly the positive steps that some individuals, companies and the ABPI had taken in that direction. Instead of giving me the rough ride that I had been expecting, participants at the meeting asked me for suggestions about what could be done to deal with the bad reputation to which Richard Sykes had referred in his evidence to the Health Committee of the House of Commons.

Although I made one or two off the cuff suggestions at the meeting, I realized that I needed to add to this essay some suggestions for steps that might go some way to increasing confidence in the scientific integrity of the industry. So, in conclusion, here are three practical suggestions:

1 All pharmaceutical companies should join Aventis, Amgen, LEO Pharma, Otsuka, Serono and 3M Pharmaceuticals in publicly endorsing the Good Publication Practice Guidelines for Pharmaceutical Companies 9,10

2 Industry as a whole should put in place mechanisms for promoting and monitoring adherence to these guidelines, thus making clear to the public that it regards under-reporting of research as just as serious a form of scientific misconduct as fabrication of data

3 Industry should voluntarily take steps that go beyond the minimum currently being required for clinical trial registration, ${ }^{30}$ for example, by publishing full protocols at the inception of all randomized trials.

I hope that I may be able to write another essay in 5 years' time entitled 'From disillusion to optimism about the scientific integrity of the pharmaceutical industry and the people collaborating with it.' 
Acknowledgments I am grateful to Richard Sykes, Richard Tiner, Elizabeth Wager, Mike Wallace, Frank Wells, Jan Vandenbroucke, and participants at the ABPI meeting held at BMA House on 28 February 2006, for helping me to ensure that this account is accurate.

\section{Competing interests None declared.}

Note Listen to an audio interview with Iain Chalmers on [http://www.jrsm.org]

\section{REFERENCES}

1 National Perinatal Epidemiology Unit. A Classified Bibliography of Controlled Trials In Perinatal Medicine 1940-1984. Oxford: Oxford University Press (for the World Health Organization), 1985

2 Simes RJ. Publication bias: the case for an international registry of clinical trials. J Clin Oncology 1986;4:1529-41

3 Hetherington J, Dickersin K, Chalmers I, Meinert CL. Retrospective and prospective identification of unpublished controlled trials: lessons from a survey of obstetricians and pediatricians. Pediatrics 1989;84:374-80

4 Chalmers I. Under-reporting research is scientific misconduct. JAMA 1990;263:1405-8

5 Hemminki E. Study of information submitted by drug companies to licensing authorities. BMJ 1980;280:833-6

6 Lock S, Wells F. Preface to the second edition. In: Lock S, Wells F, eds. Fraud and Misconduct In Medical Research. London: BMJ Publishing Group, 1996:xi-xii

7 Sykes R. Being a modern pharmaceutical company. BMJ 1998; 317:1172

8 Gibbs T, Wager E. Realities of trial registration: the Glaxo Wellcome experience. Int J Pharmaceut Med 2000;14:203-5

9 Wager E, Field EA, Grossman L. Good Publication Practice for pharmaceutical companies. Curr Med Res Opinion 2003;19:149-54

10 [http://www.gpp-guidelines.org]

11 Faculty of Pharmaceutical Medicine. Ethical Issues Working Group. Ethics in pharmaceutical medicine. Int J Pharmaceut Med 1998;12:193-8

12 Wells F, Lunnon MW. First Report of the Ethics Sub-Group. Society of Pharmaceutical Medicine. Int J Pharmaceut Med 2000;14:58-64

13 Melander H, Ahlqvist-Rastad J, Meijer G, Beermann B. Evidence b(i)ased medicine - selective reporting from studies sponsored by pharmaceutical industry: review of studies in new drug applications. BMJ 2003;326:1171-3

14 Djulbegovic B, Lacevic M, Cantor A, et al. The uncertainty principle and industry-sponsored research. Lancet 2000;356:635-8
15 Lexchin J, Bero LA, Djulbegovic B, Clark O. Pharmaceutical industry sponsorship and research outcome and quality: systematic review. BMJ 2003;326:1167-70

16 Bhandari M, Busse JW, Jackowski D, et al. Association between industry funding and statistically significant pro-industry findings in medical and surgical randomized trials. Can Med Assoc J 2004;170:47780

17 Gardner W, Lidz CW. Failures to publish pharmaceutical clinical trials. Proceedings of The 5th International Congress On Peer Review and Biomedical Publication, Chicago, September 2005.

18 Yank V, Rennie D, Bero L. Are authors' financial ties with pharmaceutical companies associated with positive results or conclusions in metaanalyses on antihypertensive medications? Proceedings of The 5th International Congress On Peer Review and Biomedical Publication, Chicago, September 2005.

19 Jørgensen AW, Gøtzche P. Sponsorship, bias, and methodology: Cochrane reviews compared with industry-sponsored meta-analyses of the same drugs. Proceedings of The 5th International Congress On Peer Review and Biomedical Publication, Chicago, September 2005.

20 Heres S, Davis J, Maino K, Jetzinger E, Kissling W, Leucht S. Why olanzapine beats risperidone, risperidone beats quetiapine, and quetiapine beats olanzapine: an exploratory analysis of head to head comparison studies of second generation anti-psychotics. Am J Psychiat 2006;163:185-94

21 Fišter K. At the frontier of biomedical publication: Chicago 2005. BMJ 2006;331:838-40

22 Chalmers I. In the dark. Drug companies should be forced to publish all the results of clinical trials. How else can we know the truth about their products. New Scientist 6 March 2004:19

23 Pearn J, Chalmers I. Publish and be applauded. New Scientist 6 January 1996:40.

24 Herxheimer A. Open access to industry's clinically relevant data. BMJ 2004;329:64-5

25 Zarin DA, Tse T, Ide NC. Trial registration at ClinicalTrials.gov between May and October 2005. N Engl J Med 2006;353:2779-87

26 House of Commons Health Committee. The Influence of The Pharmaceutical Industry, 4th Report of Session 2004-05. London: Stationery Office, 2005

27 Angell M. The Truth About The Drug Companies: How They Deceive Us and What To Do About It. New York: Random House, 2004

28 Vandenbroucke JP. Without new rules for industry-sponsored research, science will cease to exist. Rapid response on bmj.com, posted 14 December 2005 [http://bmj.bmjjournals.com/cgi/ eletters/331/7529/1350]

29 Kassirer J. On The Take: How Medicine's Complicity With Big Business Can Endanger Your Health. New York: Oxford University Press, 2004

30 Sim I, Chan A-W, Gülmezoğlu AM, Evans T, Pang T. Clinical trial registration: transparency is the watchword. Lancet 2006;367:1631-3 